\title{
Recent advances in understanding and combatting Mycoplasma genitalium
}

\author{
Joanne Peel ${ }^{1 *}$ Ei Aung ${ }^{1,2}$ Stephanie Bond ${ }^{1}$ Catriona Bradshaw ${ }^{1,2}$ \\ ${ }^{1}$ Melbourne Sexual Health Centre, Alfred Health, Melbourne, VIC, Australia \\ ${ }^{2}$ Central Clinical School, Faculty of Medicine, Nursing and Health Sciences, Monash University, Melbourne, VIC, Australia
}

\begin{abstract}
Mycoplasma genitalium has emerged over the last 30 years as a sexually transmitted infection (STI). As data have accumulated, our understanding of this pathogen and its role in disease continues to evolve. This in turn creates new challenges and complexities. Questions remain regarding the natural history of M. genitalium, its contribution to disease and long-term sequelae. A decline in cure rates for first-line anti-microbials has been observed. This is likely in part due to high usage of single-dose azithromycin in the sexual health field but also due to the intrinsic ability of $M$. genitalium to rapidly acquire anti-microbial resistance. Consequently, the term 'the new STI superbug' is not infrequently used by the media to describe this pathogen. Currently available antibiotics have side effects that, though rare, are potentially serious. This leads to inherent questions regarding the benefit of testing for and treating M. genitalium, particularly in asymptomatic individuals or in genital syndromes where the benefit of treatment is not well established. In this review, we summarize the most recent evidence and literature regarding M. genitalium and explore areas of research where disparities exist. We discuss the contribution of M. genitalium to genital syndromes, particularly those where data are conflicting, in order to inform indications for testing and treatment. Avoidance of increasing anti-microbial resistance with astute anti-microbial stewardship is paramount if we are to successfully manage M. genitalium infection. We examine the state of play regarding anti-microbial resistance and how to combat this, including currently available anti-microbials, resistance-guided therapy and novel therapeutic approaches. We aim to provide an overview of the current understanding of M. genitalium and the implications for current clinical practise and suggestions for future research.
\end{abstract}

\section{Keywords}

Mycoplasma genitalium, anti-microbial resistance

\section{Peer Review}

The peer reviewers who approve this article are:

1. Mirja Puolakkainen, Department of Virology, University of Helsinki and Helsinki University Hospital, Finland Competing interests: No competing interests were disclosed.

2. Damon Getman, Hologic Inc., San Diego, California, USA Competing interests: Dr Getman is Senior Principal Scientist at Hologic, the manufacturer of the Aptima Mycoplasma genitalium assay.

3. Harald Moi, Faculty of Medicine, University of Oslo, Oslo, Norway.

Competing interests: No competing interests were disclosed. 
*Corresponding author: Joanne Peel (jpeel@mshc.org.au)

Competing interests: Melbourne Sexual Health Centre receives institutional funding from SpeeDx molecular diagnostics.

Grant information: The authors declare that no grants were involved in supporting this work.

Copyright: (c) 2020 Peel J et al. This is an open access article distributed under the terms of the Creative Commons Attribution License, which permits unrestricted use, distribution, and reproduction in any medium, provided the original work is properly cited.

How to cite this article: Peel J, Aung E, Bond S and Bradshaw C. Recent advances in understanding and combatting Mycoplasma genitalium. Faculty Reviews 2020 9:(3) https://doi.org/10.12703/b/9-3

Published: 30 Oct 2020, Faculty Reviews 9:(3) https://doi.org/10.12703/b/9-3 


\section{Introduction}

Mycoplasma genitalium has been recognized as a sexually transmitted infection (STI) since it was first isolated from the urethra in two men with non-gonococcal urethritis (NGU) in the early $1980 \mathrm{~s}^{1}$. It is an extremely slow-growing and fastidious organism to culture, and data regarding its association with genital syndromes accumulated more rapidly following development of the first polymerase chain reaction (PCR) test in the $1990 \mathrm{~s}^{2}$. M. genitalium is now a well-recognized cause of acute and chronic $\mathrm{NGU}$ in men ${ }^{1}$. It is an established cause of cervicitis in women and emerging evidence supports its role as a causative agent of pelvic inflammatory disease (PID) ${ }^{3}$. However, its pathogenicity at other sites, including the rectum, remains subject to debate. Although the prevalence of $M$. genitalium infection is reported to be higher among persons living with HIV (PLHIV) than in the general population ${ }^{4-6}$, the interplay of $M$. genitalium-HIV co-infection is poorly understood. Anti-microbial resistance, including the emergence of multi-drug-resistant strains, is complicating current treatment strategies and there is a clear need for use of resistance assays and new classes of anti-microbials. In this review, we provide insights into our current understanding of M. genitalium's clinical presentations in men and women and the interplay between $M$. genitalium and HIV infection. We explore implications of anti-microbial resistance for treatment strategies and novel therapeutic options.

\section{Recent developments regarding $M$. genitalium's associations with disease outcomes: understanding the role of $M$. genitalium in women}

Although there is a clear association of $M$. genitalium with cervicitis and emerging evidence supports an association with PID, further data regarding the pathogenic role of $M$. genitalium in the female genital tract are somewhat limited. Lis et al. found $M$. genitalium to be significantly associated with PID by meta-analysis (odds ratio of $2.14,95 \%$ confidence interval [CI] $1.31-3.49)^{3}$, and M. genitalium was the sole pathogen identified by cervico-vaginal PCR in $5.5 \%$ of cases of PID from 2006 to 2017 at the Melbourne Sexual Health Centre ${ }^{7}$. Although PID is a clinical diagnosis that can be subjective, M. genitalium has been detected more frequently on endometrial biopsy in women with acute endometritis ${ }^{8,9}$ than in asymptomatic controls. Overall, the reported prevalence of PID in women with M. genitalium (4.8\%) appears to be significantly less than in women with cervical Chlamydia trachomatis infection $(18.6 \%$, $P=0.006)^{10}$. Latimer et al. also reported that $M$. genitalium PID was associated with a lesser vaginal polymorphonuclear response compared with chlamydial $\mathrm{PID}^{7}$. These findings suggest that although $M$. genitalium can cause PID, it is a somewhat more indolent and less inflammatory pathogen than chlamydia. This has contributed to the uncertainty regarding the benefit of testing and treating of M. genitalium in PID, which is reflected in inconsistencies among international guidelines. The Centers for Disease Control and Prevention (US) guidelines do not routinely recommend $M$. genitalium testing for women with $\mathrm{PID}^{11}$, but it is recommended by guidelines of the British Association for Sexual Health and HIV (UK) ${ }^{12}$, the Australian Sexual Health Association (Australian) $)^{13}$ and the International
Union against Sexually Transmitted Infections (European) $)^{14}$. Standard combination PID treatment in the majority of nations does not include an agent that is likely to cure M. genitalium infections. Hence, given the mounting evidence that supports a causal role in PID, the authors of this review believe data support testing for M. genitalium in women with PID, particularly where symptoms fail to respond rapidly to presumptive treatment. This applies particularly to high-risk settings, such as STI services where the prevalence of $M$. genitalium exceeds that in the general community. Baseline testing for M. genitalium in PID ensures prompt diagnosis and appropriate pathogen-specific treatment, which can reduce long-term sequelae of untreated PID such as tubal factor infertility and poorer pregnancy outcomes. Such reproductive health sequelae have been associated with $M$. genitalium by meta-analysis, although supporting data were more limited $^{3}$. However, larger prospective studies of M. genitalium are required in women to inform public health implications and testing guidelines, particularly relating to natural history of infection and long-term sequelae of untreated infection.

\section{Contribution of $M$. genitalium to rectal and pharyngeal infection}

Among asymptomatic men who have sex with men (MSM), $M$. genitalium appears to be detected significantly more often in the rectum than in the urethra ${ }^{4,15-18}$. At the urethral site, M. genitalium is an established cause of NGU and chronic $\mathrm{NGU}^{1}$. However, data are conflicting regarding the pathogenicity of M. genitalium at the rectum, its role in the development of rectal symptoms and as a causative agent of proctitis.

M. genitalium was found to be the sole pathogen in $12 \%$ of MSM with proctitis by Bissessor et al. ${ }^{19}$ and in $17 \%$ by Ong et al..$^{20}$; the latter reported rates of $M$. genitalium-proctitis comparable to those of C. trachomatis-proctitis $(21 \%)^{20}$. Bissessor et al. also reported that MSM with proctitis had significantly higher bacterial loads than asymptomatic controls and that MSM with rectal M. genitalium were significantly more likely to be HIV-positive ${ }^{19}$. Of note, these studies were among sexual health clinic attendees, whose prevalence of $M$. genitalium generally exceeds that of the general population. Conversely, several studies have reported rectal $M$. genitalium infection to be mostly asymptomatic ${ }^{15,18,21}$, and Read et al. found no significant difference in rates of rectal M. genitalium between MSM with proctitis and those with asymptomatic rectal infection ${ }^{16}$. Therefore, evidence suggests that rectal $M$. genitalium infection can result in asymptomatic carriage and less commonly proctitis. MSM with asymptomatic rectal infection may serve as reservoirs for onward transmission, whilst risk factors for the development of proctitis may involve factors such as individual host immune response, higher M. genitalium load or concurrent HIV. Overall, more data are needed to understand the role of host immunity and how this may impact on development of symptoms and duration of $M$. genitalium infection.

Rectal co-infection with bacterial STIs is common in MSM. A recent study at the Melbourne Sexual Health Centre found that 13 to $14 \%$ of rectal samples with Neisseria gonorrhoea and 
C. trachomatis had concurrent $M$. genitalium (1 in 6 cases $)^{17}$ and that high rates of co-infection were likely to result in significant exposure of undetected $M$. genitalium to azithromycin. However, where $M$. genitalium is not contributing to symptomatology, the individual benefit of detection and treatment for M. genitalium remains unclear. Although screening for $M$. genitalium at the rectum is not currently recommended by international guidelines, the authors of this review believe that consideration should be given to testing for $M$. genitalium in men presenting with proctitis, particularly in high-risk settings such as sexual health centres or among MSM LHIV ${ }^{14}$. This does not necessarily need to be first-line but should be considered in men with proctitis who remain symptomatic after testing negative for other known pathogens. Data around pharyngeal infection are less heterogeneous; a recent meta-analysis ${ }^{17}$ provided a pooled estimate of $1 \%$ for $M$. genitalium at the pharynx in MSM $^{17,22}$ and found no support for routine testing.

\section{Recent developments regarding the association of M. genitalium with HIV}

M. genitalium is significantly more common in both women and MSM LHIV than in seronegative counterparts ${ }^{6,7,23}$. The majority of data are from retrospective studies of high-risk women, including sex workers in Africa, and limited data are from women and MSM LHIV in developed countries. For women in Africa, M. genitalium appears to be an independent risk factor for HIV acquisition, and two studies reported a twofold increased risk ${ }^{6,24}$. Currently, M. genitalium testing is not widely available in resource-poor settings, which bear a high burden of new HIV diagnoses. M. genitalium testing in female genital syndromes could be considered in resource-poor countries to reduce the burden from untreated chronic disease.

For women LHIV, chronic cervical $M$. genitalium infection has been associated with cervical secretion of pro-inflammatory infiltrates and enrichment of HIV target cells, theoretically increasing the risk of HIV transmission ${ }^{25}$. Studies among African women support this theory and have shown cervical HIV-RNA shedding to be associated with higher bacterial burdens ${ }^{26}$ or chronic $M$. genitalium infection ${ }^{25}$. However, a recent US study found no association ${ }^{27}$, suggesting that although cervical $M$. genitalium can increase risk of HIV transmission, other confounding factors, such as access to anti-retroviral therapy and serum HIV-RNA viral load, are at play.

Among MSM, it is plausible that rectal M. genitalium infection increases the risk of HIV transmission via increased rectal HIV-RNA shedding; however, there are no published data examining this association. Although Sadiq et al. found no association between NGU and increased urethral shedding of HIV-RNA ${ }^{28}$, M. genitalium was not examined specifically.

Overall, the immune-physiology of $M$. genitalium-HIV coinfection is poorly understood. The fastidious nature of M. genitalium enables it to establish chronic infection, which may assist in the evasion of host immune responses ${ }^{29}$. In addition, T-cell immunodeficiency associated with HIV may cause impaired or delayed spontaneous clearance of $M$. genitalium, which may explain the higher rates of $M$. genitalium infection we observe in PLHIV. Clinicians should maintain a lower threshold for M. genitalium testing among PLHIV, particularly those with symptoms of PID or proctitis.

\section{Current understanding of $M$. genitalium immune- physiology and the host immune response}

Most research on the host response to $M$. genitalium is taken from studies regarding female genital tract infection. Limited data exist in men or for rectal infections. In the female reproductive tract, the first cells contacted by $M$. genitalium are vaginal and cervical epithelial cells (ECs). M. genitalium rapidly attaches to these ECs and establishes high intracellular titres within hours of infection ${ }^{30}$. Immunogenic $M$. genitalium proteins activate Toll-like receptors 2 and 6, which are expressed in high numbers within $\mathrm{ECs}^{31}$. This results in the production of inflammatory cytokines and chemokines, including interleukin 6 and 8 with subsequent, rapid leukocyte and macrophage recruitment ${ }^{31}$. Although M. genitalium is susceptible to such attack, it is hypothesized that the predominantly intracellular location infers a survival advantage, somewhat enabling evasion of these host cellular immune responses ${ }^{30,31}$.

M. genitalium serum IgA and IgG antibodies are detected among infected women significantly more than among uninfected controls $^{32}$. The same finding has been demonstrated for M. genitalium $\mathrm{IgG}$ in men with $\mathrm{NGU}^{33}$. Of antigenic $M$. genitalium proteins, MgbP and MgpC are encoded by genes that exhibit extensive sequence diversity ${ }^{32}$. Interestingly, antibodies against $\mathrm{MgbP}$ and $\mathrm{MgbC}$ were predominantly detected on immunoblotting of vaginal and cervical samples in $M$. genitalium-infected women $^{32}$. It is therefore plausible that genetic evolution of these antigens enables antibody evasion, increasing the likelihood of persistent infection.

\section{Recent advances in our understanding of anti- microbial resistance in $M$. genitalium}

M. genitalium has intrinsically limited susceptibility to many commonly used anti-microbials because of its lack of a peptidoglycan-containing cell wall ${ }^{34}$. Therefore, treatment options are largely restricted to agents that target protein synthesis or DNA replication such as macrolides, tetracyclines, ketolides, streptogramins and extended-spectrum fluoroquinolones. Unfortunately, however, $M$. genitalium has shown a marked propensity to rapidly acquire resistance to available treatment options. Resistance to azithromycin, the most commonly used anti-microbial for M. genitalium, is due to mutations in the $23 \mathrm{~S}$ ribosomal RNA molecule within the 50S subunit of the bacterial ribosome. These single-nucleotide polymorphisms (SNPs) in position 2058 and 2059 (Escherichia coli numbering) of the $23 \mathrm{~S}$ ribosomal RNA gene result in high-level resistance to azithromycin. Macrolide resistance develops de novo in at least $12 \%$ of M. genitalium infections following single-dose $1 \mathrm{~g}$ azithromycin ${ }^{35,36}$. Some, but not all, data suggest that extended regimens of azithromycin may result in less selected resistance ${ }^{35,36}$. The widespread use of azithromycin in the STI field, particularly syndromically as 
a $1 \mathrm{~g}$ single dose, has led to a steep rise in macrolide resistance and marked decline in azithromycin cure over the past decade ${ }^{37}$. A recent meta-analysis has shown a rise in the global prevalence of macrolide resistance mutations from $10 \%$ before 2010 to $51 \%$ in $2017^{38}$, and the greatest increase was in the countries in the Western Pacific region $(9-68 \%)^{16,38}$. Macrolide-resistant M. genitalium infections were also more common in MSM $(69 \%)$ than in heterosexual men $(40 \%)^{39}$, likely reflecting the higher use of azithromycin in this population to treat STIs.

Although the contribution of resistance mutations to failure of extended-spectrum fluoroquinolones has been harder to determine, data support an association between failure of moxifloxacin and sitafloxacin and a number of SNPs in the ParC region of the quinolone resistance-determining region, particularly at positions S83I and D87N. Concurrent GyrA mutations appear to increase the risk of failure of both agents ${ }^{39}$. Although moxifloxacin was highly effective for macrolide-resistant $M$. genitalium when first used in $2003^{40}$, treatment failures were first reported in $2008^{41}$, and meta-analysis has shown a decline in cure from $100 \%$ in studies prior to 2010 to $89 \%$ subsequently ${ }^{42}$. Although estimates of the global prevalence of fluoroquinolone resistance mutations $(8 \%)$ are far lower than for macrolides, the highest resistance is again reported in countries in the Western Pacific region $(14 \%)^{38}$. The emergence of dual-class-resistant strains poses considerable challenges to effective treatment and control of M. genitalium, and estimates are $3 \%$ globally but $7 \%$ in countries in the Western Pacific ${ }^{38}$.

\section{Strategies to improve treatment and control of M. genitalium: when to test and use of resistance assays}

The prevalence of $M$. genitalium is similar to that of chlamydia, particularly in sexual health clinic attendees. However, significant complexities and concerns regarding treatment of asymptomatic infection mean that screening cannot be recommended at present. These include access to and cost of treatment, increasing anti-microbial resistance and associated drug toxicities $^{20,21}$. Limited data exist regarding the natural history of $M$. genitalium and long-term sequelae of asymptomatic infection, and therefore priority lies with preserving currently available anti-microbials for the treatment of infections causing pathology and disease. The risk is that treatment of asymptomatic infection would cause iatrogenic complications without a clear benefit of microbiological cure. Until more efficacious drug regimens are available with fewer and less serious side effects, testing for $M$. genitalium should be limited to clinical scenarios supported by recent evidence. These include men with NGU, women with cervicitis or PID and MSM with proctitis (taking into consideration discussion points earlier in the article). Sexual contacts of confirmed cases, regardless of symptoms, should be offered testing and treatment, particularly where a sexual relationship is ongoing and risk of re-infection remains high. Wherever possible, nucleic acid amplification test/PCR assays, which enable simultaneous detection of macrolide resistance, should be used. This enables selection of antibiotics on the basis of evidence of macrolide resistance and reduces inappropriate antibiotic exposure and de novo resistance. Published evidence supports the benefits of macrolide resistance assays in clinical practice ${ }^{43,44}$, as detection of SNPs in the $23 \mathrm{~S}$ ribosomal RNA gene of $M$. genitalium confers high-level resistance to azithromycin ${ }^{45}$. However, although detection of quinolone resistance mutations in the ParC gene with or without GyrA genes have been associated with failure of moxifloxacin and sitafloxacin ${ }^{39}$, cure has also been reported in the presence of these mutations, and the role of these assays in directing treatment strategies is less clear at present $^{46}$.

\section{Anti-microbials on the horizon}

The limited susceptibility and rapid acquisition of anti-microbial resistance have posed significant issues for treatment and control in $M$. genitalium and have led to investigation of a number of registered agents. Pristinamycin, a streptogramin that arrests protein synthesis, was evaluated in a case series against macrolide-resistant $M$. genitalium strains but achieved only $75 \%$ cure when used as either a $1 \mathrm{~g}$ dose four times daily or $1 \mathrm{~g}$ three times daily in combination with doxycycline $100 \mathrm{mg}$ twice daily for 10 days ${ }^{47,48}$. With limited availability in many countries, its use has generally been restricted to cases of dual-class resistance or where fluoroquinolones are contraindicated, including pregnancy and breast-feeding. Minocycline, a tetracycline, appears to have more favourable mean inhibitory concentrations (MICs) than doxycycline for M. genitalium and has been reported to cure four patients in Japan and the US who had failed treatment with both a macrolide and a fluoroquinolone when used as an extended 14-day regimen (100 mg twice daily $)^{49,50}$. Owing to its low cost and ease of availability, more data on this agent are needed, and a recent case series in Melbourne reported $71 \%$ (95\% CI 54-85\%) cure in 35 patients with macrolide-resistant M. genitalium who had failed moxifloxacin ${ }^{48}$. Spectinomycin, an aminocyclitol aminoglycoside, has been evaluated in a single patient who failed a number of anti-microbials and had a contraindication to fluoroquinolones. Based on favourable MIC data, it was used empirically in a $2 \mathrm{~g}$ intramuscularly daily dose for 7 days and achieved microbial cure ${ }^{51}$. Limited availability, high cost and administration via daily intramuscular injections create considerable barriers to its use and will impact greatly on further evaluation of this agent for $M$. genitalium.

Several new anti-microbials, including drugs from new classes, have emerged in the past decade. Although research and development is focused on infections with a high market yield, including community-acquired pneumonia, and priority STIs, such as $N$. gonorrhoea, their target profile has suggested activity against M. genitalium. The first of these was the fluoroketolide solithromycin. This was assessed in a limited number of patients with $M$. genitalium infections before concerns regarding hepatoxicity impacted on further evaluation. In vitro studies showed that solithromycin MICs were several dilutions lower than those of azithromycin for macrolide-resistant M. genitalium isolates, but some cross-resistance was evident ${ }^{52}$. Trials for solithromycin in $N$. gonorrhoea included a small number of $M$. genitalium co-infections, where a dose of $1200 \mathrm{mg}$ cleared six out of seven M. genitalium infections but $1 \mathrm{~g}$ cleared only one out of 
three ${ }^{53}$. Lefamulin is a pleuromutilin that recently received approval from the US Food and Drug Administration for the treatment of community-acquired pneumonia. It binds to the $50 \mathrm{~S}$ bacterial ribosome to inhibit protein synthesis, a mechanism of action that differs from that of macrolides, hence limiting cross-resistance. In vitro studies showed favourable MICs in macrolide-susceptible and -resistant $M$. genitalium strains and hence lefamulin is a promising agent for the treatment of M. genitalium and has additional activity against gonorrhoea ${ }^{54}$.

Lastly, a number of investigational fluoroquinolones, DNA gyrase and topoisomerase II inhibitors in the pipeline are entering trials for $N$. gonorrhoea. Zoliflodacin is a novel spiropyrimidinetrione and topoisomerase II inhibitor that inhibits DNA biosynthesis with a distinct mode of action that differs from that of other available anti-microbials. In vitro studies against $47 M$. genitalium isolates, including moxifloxacin-resistant strains, revealed only one strain with increased MICs (4 mg/L) and potential resistance to zoliflodacin ${ }^{55}$. Overall, the authors considered zoliflodacin to be more potent than moxifloxacin and no cross-resistance was found between the two classes of topoisomerase II inhibitors. Zoliflodacin is active against both $N$. gonorrhoeae and C. trachomatis and therefore holds considerable appeal as a candidate for the syndromic management of STIs. Gepotidacin, a novel triazaacenaphthylene topoisomerase II inhibitor in trials against $N$. gonorrhoea, inhibits DNA replication via an alternate mechanism and target of action to fluoroquinolones, theoretically resulting in limited cross-resistance with other quinolones. In vitro studies demonstrated high activity against gonococcal strains and lower MICs than moxifloxacin in a limited number of $M$. genitalium isolates ${ }^{56,57}$, but more data are needed.

\section{Sequenced and combination strategies to improve cure}

Doxycycline achieves cure rates of less than $30 \%$ in M. genitalium infections. However, studies have shown that the use of doxycycline for 1 week prior to resistance-guided therapy significantly lowers bacterial load and achieves higher cure rates than treatment with a macrolide or fluoroquinolone alone ${ }^{43}$. Cure rates in the order of $95 \%$ for sequential doxycycline-extended azithromycin and $92 \%$ for doxycycline-moxifloxacin were observed by Durukan et al. ${ }^{44}$. Sitafloxacin, a fourth-generation fluoroquinolone, has more favourable MICs than moxifloxacin and in vitro has been shown to cure some $M$. genitalium strains harbouring quinolone resistance mutations that reduce moxifloxacin susceptibility ${ }^{2,44}$. However, cure rates similar to those achieved with moxifloxacin (92\%) were achieved using sequential doxycycline-sitafloxacin therapy in Melbourne for the treatment of macrolide-resistant $M$. genitalium $^{43}$.
Combinations of anti-microbials have been used to optimize cure and minimize de novo resistance of bacterial infections with a propensity to develop anti-microbial resistance, such as tuberculosis and methicillin-resistant Staphylococcus aureus. The Melbourne Sexual Health Centre group recently trialled combination therapy with doxycycline (100 mg twice a day) and sitafloxacin (100 mg twice a day) for 7 days as a novel approach to treat highly resistant $M$. genitalium strains ${ }^{57}$. This regimen was well tolerated and cured 11 out of 12 infections that had failed prior treatment with sequenced doxycycline-moxifloxacin and doxycycline-pristinamycin ${ }^{57}$. Although sitafloxacin is more likely than moxifloxacin to cure an infection carrying an S83I (par C) mutation, concurrent gyrA mutations, particularly M95I, increase the risk of sitafloxacin failure. In this study, combination doxycycline+sitafloxacin cured $M$. genitalium strains with gyrA mutations, suggesting synergy between the two antimicrobials. Although this is promising, more data are needed to inform the use of combination doxycycline+sitafloxacin therapy to treat highly resistant $M$. genitalium strains.

\section{Conclusions}

M. genitalium continues to pose complex clinical diagnostic and treatment challenges. Much remains unknown regarding its pathogenic role and the host immune response which appears to vary between both individuals and sites of infection. In this manner, it has proven itself to be rather different from other bacterial STIs such as C. trachomatis and N. gonorrhoea. Further evidence is required to fully understand its role in female reproductive health sequelae and proctitis. A more detailed understanding of the natural history of asymptomatic, untreated infection is needed to inform screening guidelines, particularly in young women where infection could result in adverse reproductive health outcomes. With anti-microbial resistance increasing expeditiously, it is possible that M. genitalium will become the first 'untreatable' STI. Judicial anti-microbial prescribing in all health-care settings with specific measures to reduce de novo resistance in $M$. genitalium strains is imperative. This calls for widespread clinician education in sexual health and primary care specialities regarding the use of our most effective first-line strategies. Although new drugs show promise, many will not be available for some time and may prove costly and difficult to access, particularly for primary health-care providers. Early data indicate that combination therapy with sitafloxacin and doxycycline is well tolerated and effective for highly resistant $M$. genitalium strains, but access to sitafloxacin is limited in many parts of the world. In the meantime, efforts should be directed to epidemiological surveillance to quantify the burden of $M$. genitalium infection and determine trends in resistance by population and geographical area. This is essential to further inform the development and revision of local and national treatment guidelines and strategies. 
1. Taylor-Robinson D, Jensen JS: Mycoplasma genitalium: From Chrysalis to multicolored butterfly. Clin Microbiol Rev. 2011; 24(3): 498-514. PubMed Abstract | Publisher Full Text | Free Full Text

2. Jensen JS, Bradshaw C: Management of Mycoplasma genitalium infections - can we hit a moving target? BMC Infect Dis. 2015; 15: 343 . PubMed Abstract | Publisher Full Text | Free Full Text

3. Lis R, Rowhani-Rahbar A, Manhart LE: Mycoplasma genitalium Infection and Female Reproductive Tract Disease: A Meta-analysis. Clin Infect Dis. 2015; 61(3): 418-26.

PubMed Abstract | Publisher Full Text

4. Mahlangu MP, Müller EE, Venter JME, et al:: The Prevalence of Mycoplasma genitalium and Association With Human Immunodeficiency Virus Infection in Symptomatic Patients, Johannesburg, South Africa, 2007-2014. Sex Transm Dis. 2019; 46(6): 395-9.

PubMed Abstract | Publisher Full Text | Free Full Text |

Faculty Opinions Recommendation

5. Mavedzenge SN, Van der Pol B, Weiss HA, et al.: The association between Mycoplasma genitalium and HIV-1 acquisition in African women. AIDS. 2012; 26(5): 617-24.

PubMed Abstract | Publisher Full Text

6. Ong JJ, Magooa MP, Chikandiwa A, et al.: Clinical Characteristics of Mycoplasma genitalium and the Usefulness of Syndromic Managemen Among Women Living With Human Immunodeficiency Virus. Sex Transm Dis. 2019; 46(12): 801-4.

PubMed Abstract | Publisher Full Text

7. Latimer RL, Read TRH, Vodstrcil LA, et al:: Clinical Features and Therapeutic Response in Women Meeting Criteria for Presumptive Treatment for Pelvic Inflammatory Disease Associated With Mycoplasma genitalium. Sex Transm Dis. 2019; 46(2): 73-9.

PubMed Abstract | Publisher Full Text

8. Cohen CR, Manhart LE, Bukusi EA, et al:: Association between Mycoplasma genitalium and acute endometritis. Lancet. 2002; 359(9308): 765-6. PubMed Abstract | Publisher Full Text

9. Haggerty CL, Totten PA, Astete SG, et al.: Mycoplasma genitalium among women with nongonococcal, nonchlamydial pelvic inflammatory disease. Infect Dis Obstet Gynecol. 2006; 2006: 30184 PubMed Abstract | Publisher Full Text | Free Full Text

10. Bjartling C, Osser S, Persson K: Mycoplasma genitalium in cervicitis and pelvic inflammatory disease among women at a gynecologic outpatient service. $\mathrm{Am} \mathrm{J}$ Obstet Gynecol. 2012; 206(6): 476.e1-476.e8.

PubMed Abstract | Publisher Full Text

11. Centers for Disease Control and Prevention: Emerging Issues - 2015 STD Treatment Guidelines, Mycoplasma genitalium. Reference Source

12. British Association for Sexual Health and HIV BASHH Guidelines 2018, Urethritis and cervicitis, updated Nov 2019. Reference Source

13. Australian Sexual Health Alliance, Australian STI Management Guidelines 2018, Mycoplasma genialium.

Reference Source

14. Jensen JS, Cusini M, Gomberg M, et al.: 2016 European guideline on Mycoplasma genitalium infections. J Eur Acad Dermatol Venereol. 2016; 30(10): $1650-6$.

PubMed Abstract | Publisher Full Text

15. Soni S, Alexander S, Verlander N, et al:: The prevalence of urethral and rectal Mycoplasma genitalium and its associations in men who have sex with men attending a genitourinary medicine clinic. Sex Transm Infect. 2010; 86(1): 21-4 PubMed Abstract | Publisher Full Text

16. Read TRH, Murray GL, Danielewski JA, et al:: Symptoms, Sites, and Significance of Mycoplasma genitalium in Men Who Have Sex with Men. Emerg Infect Dis. 2019; 25(4): 719-27.

PubMed Abstract | Publisher Full Text | Free Full Text

17. Latimer RL, Vodstrcil L, de Petra V, et al.: Extragenital Mycoplasma genitalium infections among men who have sex with men. Sex Transm Infect. 2020; 96(1): 10-8.

PubMed Abstract | Publisher Full Text

18. Bradshaw CS, Fairley CK, Lister NA, et al:: Mycoplasma genitalium in men who have sex with men at male-only saunas. Sex Transm Infect. 2009; 85(6): 432-5. PubMed Abstract | Publisher Full Text

19. Bissessor M, Tabrizi SN, Bradshaw CS, et al: The contribution of Mycoplasm genitalium to the aetiology of sexually acquired infectious proctitis in men who have sex with men. Clin Microbiol Infect. 2016; 22(3): 260-5. PubMed Abstract | Publisher Full Text

20. Ong JJ, Aung E, Read TRH, et al.: Clinical Characteristics of Anorectal Mycoplasma genitalium Infection and Microbial Cure in Men Who Have Sex With Men. Sex Transm Dis. 2018; 45(8): 522-6. PubMed Abstract | Publisher Full Text

21. Sonnenberg P, Ison CA, Clifton S, et al.: Epidemiology of Mycoplasma genitalium in British men and women aged 16-44 years: Evidence from the third National Survey of Sexual Attitudes and Lifestyles (Natsal-3). Int J Epidemiol. 2015; 44(6): 1982-94.

PubMed Abstract | Publisher Full Text | Free Full Text

22. Latimer RL, Shilling HS, Vodstrcil LA, et al:: Prevalence of Mycoplasma genitalium by anatomical site in men who have sex with men: A systematic review and meta-analysis. Sex Transm Infect. 2020; sextrans-2019-054310. PubMed Abstract | Publisher Full Text

23. Vandepitte J, Weiss HA, Bukenya J, et al:: Association between Mycoplasma genitalium infection and HIV acquisition among female sex workers in Uganda: Evidence from a nested case-control study. Sex Transm Infect. 2014; 90(7): 545-9.

PubMed Abstract | Publisher Full Text | Free Full Text

24. Dehon PM, Hagensee ME, Sutton KJ, et al.: Histological Evidence of Chronic Mycoplasma genitalium-Induced Cervicitis in HIV-Infected Women: A Retrospective Cohort Study. J Infect Dis. 2016; 213(11): 1828-35. PubMed Abstract | Publisher Full Text | Free Full Text

25. Manhart LE, Mostad SB, Baeten JM, et al.: High Mycoplasma genitalium Organism Burden Is Associated with Shedding of HIV 1 DNA from the Cervix. $J$ Infect Dis. 2008; 197(5): 733-6.

PubMed Abstract | Publisher Full Text | Free Full Text

26. Sadiq ST, Taylor S, Copas AJ, et al:: The effects of urethritis on seminal plasma HIV-1 RNA loads in homosexual men not receiving antiretroviral therapy. Sex Transm Infect. 2005; 81(2): 120-3.

PubMed Abstract | Publisher Full Text | Free Full Text

27. Gatski M, Martin DH, Theall K, et al:: Mycoplasma genitalium infection among HIV-positive women: prevalence, risk factors and association with vaginal shedding. Int J STD AIDS. 2011; 22(3): 155-159. PubMed Abstract | Publisher Full Text | Free Full Text

28. Horner PJ, Martin DH: Mycoplasma genitalium Infection in Men. J Infect Dis. 2017; 216(suppl_2): S396-S405.

PubMed Abstract | Publisher Full Text | Free Full Text |

Faculty Opinions Recommendation

29. McGowin CL, Popov VL, Pyles RB: Intracellular Mycoplasma genitalium infection of human vaginal and cervical epithelial cells elicits distinct patterns of inflammatory cytokine secretion and provides a possible survival niche against macrophage-mediated killing. BMC Microbiol. 2009; 9: 139. PubMed Abstract | Publisher Full Text | Free Full Text

30. McGowin CL, Ma L, Martin DH, et al:: Mycoplasma genitalium-Encoded MG309 Activates NF- $\kappa$ B via Toll-Like Receptors 2 and 6 To Elicit Proinflammatory Cytokine Secretion from Human Genital Epithelial Cells. Infect Immun. 2009, 77(3): 1175-81.

PubMed Abstract | Publisher Full Text | Free Full Text

31. Iverson-Cabral SL, Manhart LE, Totten PA: Detection of Mycoplasma genitaliumreactive cervicovaginal antibodies among infected women. Clin Vaccine Immunol. 2011; 18(10): 1783-6.

PubMed Abstract | Publisher Full Text | Free Full Text

32. Svenstrup HF, Jensen JS, Gevaert K, et al:: Identification and Characterization of Immunogenic Proteins of Mycoplasma genitalium. Clin Vaccine Immunol. 2006 13(8): 913-22.

PubMed Abstract | Publisher Full Text | Free Full Text

33. Bradshaw CS, Jensen JS, Waites KB: New Horizons in Mycoplasma genitalium Treatment. J Infect Dis. 2017; 216(suppl_2): S412-S419. PubMed Abstract | Publisher Full Text | Free Full Text | Faculty Opinions Recommendation

34. Horner $\mathrm{P}$, Ingle $\mathrm{SM}$, Garrett $\mathrm{F}$, et al:: Which azithromycin regimen should be used for treating Mycoplasma genitalium?: A meta-analysis. Sex Transm Infect 2018; 94(1): 14-20.

PubMed Abstract | Publisher Full Text | Faculty Opinions Recommendation

35. Read TRH, Fairley CK, Tabrizi SN, et al:: Azithromycin 1.5g Over 5 Days Compared to 1g Single Dose in Urethral Mycoplasma genitalium: Impact on Treatment Outcome and Resistance. Clin Infect Dis. 2017; 64(3): 250-6. PubMed Abstract | Publisher Full Text

36. Lau A, Bradshaw CS, Lewis D, et al:: The Efficacy of Azithromycin for the Treatment of Genital Mycoplasma genitalium: A Systematic Review and Metaanalysis. Clin Infect Dis. 2015; 61(9): 1389-99.

PubMed Abstract | Publisher Full Text

37. Machalek DA, Tao $\mathrm{Y}$, Shilling $\mathrm{H}$, et al:: Prevalence of mutations associated with resistance to macrolides and fluoroquinolones in Mycoplasma genitalium A systematic review and meta-analysis. Lancet Infect Dis. 2020; S14733099(20)30154-7. 3099(20)30154-7.
PubMed Abstract | Publisher Full Text

38. Murray GL, Bodiyabadu K, Danielewski J, et al.: Moxifloxacin and Sitafloxacin Treatment Failure in Mycoplasma genitalium Infection: Association with parC Mutation G248T (S83I) and Concurrent gyrA Mutations. J Infect Dis. 2020; 221(6): 1017-24. 221(6): 1017-24.
PubMed Abstract | Publisher Full Text

39. Bradshaw CS, Jensen JS, Tabrizi SN, et al.: Azithromycin failure in Mycoplasma 
genitalium urethritis. Emerg Infect Dis. 2006; 12(7): 1149-52. PubMed Abstract | Publisher Full Text | Free Full Text

40. Couldwell DL, Tagg KA, Jeoffreys NJ, et al.: Failure of moxifloxacin treatment in Mycoplasma genitalium infections due to macrolide and fluoroquinolone resistance. Int J STD AIDS. 2013; 24(10): 822-8. PubMed Abstract | Publisher Full Text

41. CLi Y, Le WJ, Li S, et al.: Meta-analysis of the efficacy of moxifloxacin in treating Mycoplasma genitalium infection. Int J STD AIDS. 2017; 28(11): 1106-14.

PubMed Abstract | Publisher Full Text | Faculty Opinions Recommendation

42. Read TRH, Fairley CK, Murray GL, et al:: Outcomes of Resistance-guided Sequential Treatment of Mycoplasma genitalium Infections: A Prospective Evaluation. Clin Infect Dis. 2019; 68(4): 554-60.

PubMed Abstract | Publisher Full Text | Free Full Text

43. Durukan D, Read TRH, Murray G, et al:: Resistance-Guided Antimicrobial Therapy Using Doxycycline-Moxifloxacin and Doxycycline-2.5 g Azithromycin for the Treatment of Mycoplasma genitalium Infection: Efficacy and Tolerability. Clin Infect Dis. 2020; 71(6): 1461-1468. PubMed Abstract | Publisher Full Text

44. Jensen JS, Bradshaw CS, Tabrizi SN, et al: Azithromycin treatment failure in Mycoplasma genitalium-positive patients with nongonococcal urethritis is associated with induced macrolide resistance. Clin Infect Dis. 2008; 47(12): 1546-53.

PubMed Abstract | Publisher Full Text | Faculty Opinions Recommendation

45. Manhart LE, Jensen JS: Quinolone Resistance-Associated Mutations in Mycoplasma genitalium: Not Ready for Prime Time. Sex Transm Dis. 2020; 47(3): 199-201.

PubMed Abstract | Publisher Full Text | Faculty Opinions Recommendation

46. Read TRH, Jensen JS, Fairley CK, et al.: Use of Pristinamycin for MacrolideResistant Mycoplasma genitalium Infection. Emerging Infect Dis. 2018; 24(2): 328-35.

PubMed Abstract | Publisher Full Text | Free Full Text

47. Doyle M, Vodstrcil LA, Plummer EL, et al.: Nonquinolone Options for the Treatment of Mycoplasma genitalium in the Era of Increased Resistance. Open Forum Infect Dis. 2020; 7(8): ofaa291. PubMed Abstract | Publisher Full Text | Free Full Text

48. Claser AM, Geisler WM, Ratliff AE, et al.: Two cases of multidrug-resistant genitourinary Mycoplasma genitalium infection successfully eradicated with minocycline. Int J STD AIDS. 2019; 30(5): 512-4.

PubMed Abstract | Publisher Full Text | Faculty Opinions Recommendation
49. Deguchi T, Ito S, Yasuda M, et al: Emergence of Mycoplasma genitalium with clinically significant fluoroquinolone resistance conferred by amino acid changes both in GyrA and ParC in Japan. J Infect Chemother. 2017; 23(9): 648-50.

PubMed Abstract | Publisher Full Text | Faculty Opinions Recommendation

50. Falk L, Jensen JS: Successful outcome of macrolide-resistant Mycoplasma genitalium urethritis after spectinomycin treatment: A case report. $J$ Antimicrob Chemother. 2017; 72(2): 624-5.

PubMed Abstract | Publisher Full Text | Faculty Opinions Recommendation

51. Waites KB, Crabb DM, Duffy LB: Comparative In Vitro Susceptibilities of Human Mycoplasmas and Ureaplasmas to a New Investigational Ketolide, CEM-101. Antimicrob Agents Chemother. 2009; 53(5): 2139-41.

PubMed Abstract | Publisher Full Text | Free Full Text

52. Hook EW, Golden M, Jamieson BD, et al:: A Phase $\mathbf{2}$ Trial of Oral Solithromycin $1200 \mathrm{mg}$ or $1000 \mathrm{mg}$ as Single-Dose Oral Therapy for Uncomplicated Gonorrhea. Clin Infect Dis. 2015; 61(7): 1043-8.

PubMed Abstract | Publisher Full Text

53. Paukner S, Gruss A, Jensen JS: In Vitro Activity of Lefamulin against Sexually Transmitted Bacterial Pathogens. Antimicrob Agents Chemother. 2018; 62(5): e02380-17.

PubMed Abstract | Publisher Full Text | Free Full Text | Faculty Opinions Recommendation

54. Damião Gouveia AC, Unemo M, Jensen JS: In vitro activity of zoliflodacin (ETX0914) against macrolide-resistant, fluoroquinolone-resistant and antimicrobial-susceptible Mycoplasma genitalium strains. J Antimicrob Chemother. 2018; 73(5): 1291-4

PubMed Abstract | Publisher Full Text | Faculty Opinions Recommendation

55. N Jacobsson S, Golparian D, Scangarella-Oman N, et al:: In vitro activity of the novel triazaacenaphthylene gepotidacin (GSK2140944) against MDR Neisseria gonorrhoeae. J Antimicrob Chemother. 2018; 73(8): 2072-7. PubMed Abstract | Publisher Full Text | Free Full Text | Faculty Opinions Recommendation

56. Waites KB, Crabb DM, Xiao L, et al:: In Vitro Activities of Gepotidacin (GSK2140944) and Other Antimicrobial Agents against Human Mycoplasmas and Ureaplasmas. Antimicrob Agents Chemother. 2017; 61(10): e01064-17. PubMed Abstract | Publisher Full Text | Free Full Text | Faculty Opinions Recommendation

57. Durukan DDM, Murray G, Bodiyabadu K, et al.: Early experience with combining doxycycline and sitafloxacin for the treatment of highly resistant Mycoplasma genitalium. Emerg Infect Dis: In Press; Accepted April 2020. 